\title{
HPV Vaccination Uptake and Administration from 2006 to 2016 in a Commercially Insured Population of the United States
}

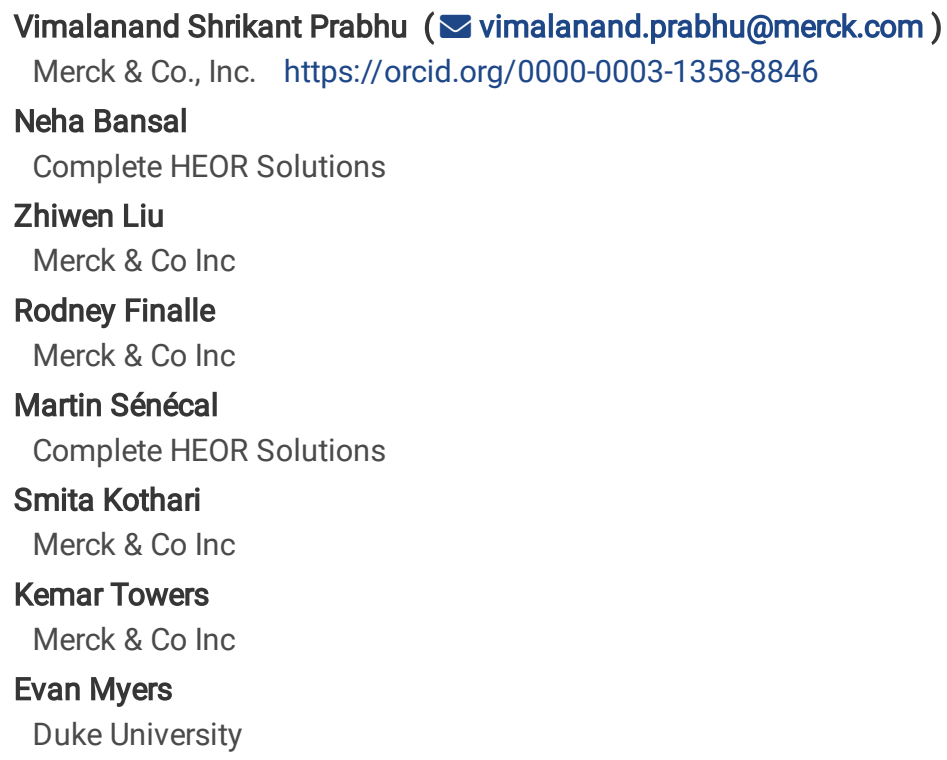

Research article

Keywords: Human papillomavirus, HPV vaccine, Vaccination uptake, Temporal trends, Sex differences, Insurance claims data

Posted Date: December 7th, 2020

DOI: https://doi.org/10.21203/rs.3.rs-56007/v1

License: (c) (i) This work is licensed under a Creative Commons Attribution 4.0 International License. Read Full License 


\section{Abstract}

\section{Background}

Human papillomavirus (HPV) infection can cause various HPV-related cancers and can be prevented through HPV vaccination. While vaccination coverage (proportion ever vaccinated) estimates are available, vaccination uptake (proportion getting their first vaccine dose in a specific year) in the United States (US) is not well-known.

\section{Methods}

We conducted a retrospective analysis of MarketScan ${ }^{\circledR}$ claims database to assess the HPV vaccination uptake in the US among the 9- to 26years-olds from 2006 to 2016. The annual uptake was the ratio between the number of enrollees for whom a first record of an HPV vaccine was found during the year and the total number of unique enrollees of similar age and gender identified that year.

\section{Results}

Uptake was below $1 \%$ among children turning 9 and 10 years old during the year. Since 2009 among female and since 2013 among males, annual uptake has been the highest in those turning 13 years old (19.7\% among females and 17.6\% among males in 2016). Catch-up vaccination among older adolescents and young adults increased after Advisory Committee for Immunization Practices (ACIP) recommendations, but eventually slowed down as more younger persons were vaccinated. Most young adolescents were vaccinated by pediatricians, whereas young adult women were predominantly vaccinated by obstetricians/gynecologists and young adult males by family physicians. While only about half of the adolescents had well-check visits, majority of those who initiated HPV vaccination had at least one well-check visit the same year.

\section{Conclusion}

Understanding HPV vaccination uptake can guide the development of appropriate interventions to help improve public health.

\section{Background}

Recent data indicate that approximately 14 million persons are newly infected with human papillomavirus (HPV) each year in the United States (US), and approximately 79 million persons are currently infected (1). HPV causes most of cervical pre-cancers and cervical cancers, and many vulvar, vaginal, penile, anal, and oropharyngeal cancers, and diseases such as genital warts (2). In the US, a total of 43,371 HPVassociated cancers were reported in 2015 (3). From an economic perspective, HPV was reported to be the second most expensive sexually transmitted disease after Human Immunodeficiency Virus (HIV) in terms of direct medical care costs (4).

To date, three HPV vaccines have been approved in the US for the prevention of HPV-related diseases: a quadrivalent (4vHPV), a bivalent (2vHPV), and nonavalent (9vHPV) vaccine (5-7). The 4vHPV was licensed to protect against diseases caused by HPV types $6,11,16$ and 18 , for females in 2006, and for males in 2009 (6). The 2vHPV vaccine covering types 16 and 18 became available in 2009 for females only (7). The 4vHPV was the most commonly administered HPV vaccine in the US until the 9vHPV vaccine against HPV types $6,11,16,18,31,33,45$, 52 , and 58 was approved for use in both males and females in December 2014 (6). Since the beginning of 2017, 9vHPV has been the only HPV vaccine available in the US(8)

The US Advisory Committee on Immunization Practices (ACIP) recommended routine HPV vaccination of girls at the ages of 11 or 12 in 2006 (9). Vaccination could start as early as 9 years and catch-up vaccination was recommended through age 26 years for females. In 2011 , vaccination was routinely recommended for both girls and boys and catch-up was extended for males through age 21 years (5). In June 2019 , the ACIP harmonized the upper age limit for male and female vaccination catch-up to 26 years, and recommended shared clinical decisionmaking for adults 27 through 45 years old (10). Economic models have shown that HPV vaccination of adolescents and young adults is costeffective, or cost-saving (11). Recognizing the potential of HPV vaccination in reducing the incidence of vaccine-preventable cancers, the American Cancer Society (ACS) launched an "HPV Cancer Free” public health campaign with a goal to have $80 \%$ of 13 year old girls and boys in the US fully vaccinated with HPV vaccine by 2026, 20 years after introduction of the first HPV vaccine (12). To meet the ACS goal, it is essential to understand how vaccinations occur. This includes detailed information regarding the age at which children and young adults get vaccinated, who administers the vaccine, and in what setting and visit-type, and the temporal trend around these measures. This information can guide the development of appropriate policy measures and interventions to help meet the ACS goal. Analysis of annual vaccination uptake, i.e. the proportion of persons initiating HPV vaccine in a year, can provide insights on when, where, and by whom females and males get vaccinated. This can be helpful for improving the overall vaccination coverage, which is the proportion of the population who has ever received HPV vaccination during their lifetime. Vaccination coverage has been estimated through insurance claims data $(13,14)$ and nationwide studies such as the National Health and Nutrition Examination Survey (NHANES) of the 9- to 59- years-old (15), the National 
Immunization Survey-Teen (NIS-Teen) among the 13- to 17-years-olds (16), and the National Health Interview Survey (NHIS) targeting males and females aged 19 to 26 years old (17). None of the studies provided direct estimates of the HPV vaccination uptake. Vaccinations often occur during annual well-check visits, that are recommended by the American Academy of Pediatrics for all US children (18, 19), and understanding how uptake is associated with a well-check visit is also important.

In this study, we assess HPV vaccination uptake since the first HPV vaccine was introduced in 2006 until 2016 , within the 9 to 26 years old population. We also examine who administered the vaccine, and whether vaccines are initiated during a well-check visit.

\section{Methods}

\subsection{Data Source}

This retrospective analysis was based on the IBM® MarketScan ${ }^{\circledR}$ claim database which comprises prescription data in addition to inpatient and outpatient medical utilization for millions of commercially insured individuals across the US. It was selected because of its size, geographic representativeness, and diversity of plan types. IBM provided the de-identified individual-level data which are fully compliant with U.S. privacy laws and regulations, i.e. the Health Insurance Portability and Accountability Act (HIPAA). As a result, this study was IRB exempt, and no IRB approval was necessary.

\subsection{Design, Measurements and Analysis}

The annual HPV vaccination uptake was defined as the proportion of unique enrollees who had a first claim for a dose of the HPV vaccine (Current Procedure Terminology (CPT) code: 90649 (4vHPV), 90651 (9vHPV), and 90650 (2vHPV) during the year. Each individual was counted only once. Age of the subject was determined by difference between calendar year and year of birth so that the 1997 newborns were the 9 years-olds in 2006 (the database only provides the year of birth to protect anonymity). Since the HPV vaccine is indicated at 9 years old or above, we could assume, in 2006 for example, that everyone from birth cohort 1997 who was vaccinated was 9 years old. However, in 2006, subjects from birth cohort 1996 could be vaccinated either at 9 or 10 years old depending upon whether they had the vaccine before or after their 10th birthday, and therefore were referred to as the 9-10 years old. Each year, females and males turning 9 to 26 years old were included; In other words, in 2006, enrollees who were born between 1980 (turning 26 years old) and 1997 (turning 9 years old). Women with an International Classification of Disease (ICD 9/10) code for pregnancy (Supplementary material, Table S1) recorded anytime during the year were excluded from both the numerator and the denominators of the annual uptakes. A heat map was produced reporting the uptake with red color representing lower uptake, and green color indicating higher uptake. The heat map provides a temporal trend for interpreting uptake over time.

The MarketScan ${ }^{\circledR}$ database also includes data on the type of health care provider that administered the vaccine. Healthcare providers filing the claim were regrouped in various categories; pediatricians, family physicians, neonatal specialists, obstetricians/gynecologists, and primary care physicians based on available categories in MarketScan. Since there were broad categories, some physician codes were combined and put into others category. To assess whether vaccination was initiated during well-check visits, each calendar year, children and adolescents aged 9 to 18 years old who had a medical claim associated with one of the ICD 9/10 diagnosis (primary or secondary) or CPT procedure codes listed in Supplementary material (Table S2) were identified. Those within this group who initiated HPV vaccination were also identified. Data were stratified by calendar year, age (i.e. year of birth) and gender. Analyses were performed using SAS version 9.4, and heat maps depicting uptake were created in Microsoft Excel.

\section{Results}

\subsection{HPV Vaccination Uptake}

In the Marketscan ® claims database, there were 118 million unique enrollees who turned 9 to 26 years old from 2006 to 2016 . Slightly less than half (49.4\%) were females. Figure 1 shows the age-specific annual uptake of HPV vaccination between 2006 and 2016 , for females (a) and for males (b), respectively. Birth cohort-specific uptakes can be found moving diagonally downwards from left to right across the figures. For females who turned 9 years old in 2006 , or the 1997 cohort the vaccination uptake was: $1.0 \%$ in 2008 (10-11 years old), $9.0 \%$ in 2010 (12-13 years old), 9.1\% in 2013 (16-17 years old), and 5.6\% in 2016 (18-19 years old). Among males born in 1997, the uptake was $0 \%$ until HPV vaccination was indicated for males in 2009, after which, we observe catch-up vaccination occurring: 1.1\% in 2010 (12-13 years old), $10.5 \%$ in 2013 (15-16 years old) and 5.8\% in 2016 (18-19 years old). Throughout the study period, the uptake was below $1 \%$ among children turning 9 and 10 years old during the year, while it increased gradually in adolescents turning 12 to 14 years old, reaching $19.7 \%$ of females and $17.6 \%$ of males among those turning 13 years old in 2016 . Since 2009 among female and since 2013 among males, the uptake was actually the highest at 12-13 years old (Fig. 1b and Table 1). Among females turning 16 years old and above, the uptake peaked in 2007,

Page $3 / 13$ 
when the vaccine became available, then dropped and flattened as cohorts with vaccinated persons aged. Among females turning 22 years old or more, the uptake was low, around 1.5\% in 2016. In males, the catch-up among older adolescents spread out more uniformly; The highest uptakes were observed in 2013 (among the 15-16 years old, the annual uptakes from 2011 to 2016 were respectively: $4.0 \%, 8.5 \%, 10.5 \%, 8.8 \%$, $7.9 \%$ and $8.9 \%$ ). The uptakes were $\leq 1 \%$ among males turning 22 years old or more (Fig. $1 \mathrm{~b}$ and Table 1). 
Table 1

HPV Vaccination Uptake and Well-Check Visits Among the 9- to 18-Years-Olds: 2006 to 2016

\begin{tabular}{|c|c|c|c|c|c|c|c|c|c|c|c|}
\hline & \multicolumn{11}{|c|}{ Calendar Year } \\
\hline & 2006 & 2007 & 2008 & 2009 & 2010 & 2011 & 2012 & 2013 & 2014 & 2015 & 2016 \\
\hline \multicolumn{12}{|l|}{$\begin{array}{l}\text { Females } \\
9 \text { to } \\
18 \text { years } \\
\text { old }\end{array}$} \\
\hline $\begin{array}{l}\text { Number } \\
\text { of } \\
\text { enrollees } \\
\text { who } \\
\text { initiated } \\
\text { the } \\
\text { vaccine } \\
\text { series } \\
\text { during } \\
\text { the year }\end{array}$ & 25913 & 214650 & 180162 & 166380 & 166971 & 215305 & 225899 & 218992 & 218879 & 132963 & 157527 \\
\hline $\begin{array}{l}\text { Percent } \\
\text { of } \\
\text { enrollees } \\
\text { who } \\
\text { initiated } \\
\text { the } \\
\text { vaccine } \\
\text { series } \\
\text { during } \\
\text { the year }\end{array}$ & 1.1 & 8.8 & 7.1 & 5.7 & 5.1 & 5.8 & 6.1 & 7.2 & 6.8 & 6.9 & 8.4 \\
\hline $\begin{array}{l}\text { Number } \\
\text { of } \\
\text { enrollees } \\
\text { who had } \\
\text { a well- } \\
\text { check } \\
\text { visit } \\
\text { during } \\
\text { the year }\end{array}$ & 705346 & 786193 & 858370 & 1080995 & 1226767 & 1486044 & 1530606 & 1311181 & 1425307 & 901285 & 923544 \\
\hline $\begin{array}{l}\text { Percent } \\
\text { of } \\
\text { enrollees } \\
\text { who had } \\
\text { a well- } \\
\text { check } \\
\text { visit } \\
\text { during } \\
\text { the year }\end{array}$ & 29.7 & 33.2 & 33.9 & 37.3 & 37.4 & 39.8 & 41.0 & 43.3 & 44.5 & 47.0 & 49.0 \\
\hline $\begin{array}{l}\text { Number } \\
\text { of } \\
\text { enrollees } \\
\text { who } \\
\text { initiated } \\
\text { the } \\
\text { vaccine } \\
\text { series } \\
\text { and had } \\
\text { a well- } \\
\text { check } \\
\text { visit } \\
\text { during } \\
\text { the year }\end{array}$ & 21137 & 176614 & 144495 & 137383 & 139270 & 184970 & 197813 & 194179 & 193671 & 120103 & 141897 \\
\hline
\end{tabular}




\begin{tabular}{|c|c|c|c|c|c|c|c|c|c|c|c|}
\hline & \multicolumn{11}{|c|}{ Calendar Year } \\
\hline & 2006 & 2007 & 2008 & 2009 & 2010 & 2011 & 2012 & 2013 & 2014 & 2015 & 2016 \\
\hline $\begin{array}{l}\text { Percent } \\
\text { of those } \\
\text { who } \\
\text { initiated } \\
\text { the } \\
\text { vaccine } \\
\text { series } \\
\text { during } \\
\text { the year } \\
\text { who had } \\
\text { a well- } \\
\text { check } \\
\text { visit that } \\
\text { year }\end{array}$ & 81.6 & 82.3 & 80.2 & 82.6 & 83.4 & 85.9 & 87.6 & 88.7 & 88.5 & 90.3 & 90.1 \\
\hline \multicolumn{12}{|l|}{$\begin{array}{l}\text { Males } 9 \\
\text { to } \\
18 \text { years } \\
\text { old }\end{array}$} \\
\hline $\begin{array}{l}\text { Number } \\
\text { of } \\
\text { enrollees } \\
\text { who } \\
\text { initiated } \\
\text { the } \\
\text { vaccine } \\
\text { series } \\
\text { during } \\
\text { the year }\end{array}$ & 124 & 744 & 694 & 650 & 26786 & 99984 & 212044 & 221767 & 218544 & 131005 & 159020 \\
\hline $\begin{array}{l}\text { Percent } \\
\text { of } \\
\text { enrollees } \\
\text { who } \\
\text { initiated } \\
\text { the } \\
\text { vaccine } \\
\text { series } \\
\text { during } \\
\text { the year }\end{array}$ & 0.0 & 0.0 & 0.0 & 0.0 & 0.8 & 2.6 & 5.5 & 7.0 & 6.6 & 6.6 & 8.1 \\
\hline $\begin{array}{l}\text { Number } \\
\text { of } \\
\text { enrollees } \\
\text { who had } \\
\text { a well- } \\
\text { check } \\
\text { visit } \\
\text { during } \\
\text { the year }\end{array}$ & 708350 & 771080 & 842805 & 1074213 & 1238359 & 1501173 & 1555409 & 1335685 & 1449299 & 918200 & 939500 \\
\hline $\begin{array}{l}\text { Percent } \\
\text { of } \\
\text { enrollees } \\
\text { who had } \\
\text { a well- } \\
\text { check } \\
\text { visit } \\
\text { during } \\
\text { the year }\end{array}$ & 28.5 & 30.3 & 31.9 & 35.5 & 36.1 & 38.6 & 40.1 & 42.4 & 43.4 & 46.1 & 47.9 \\
\hline $\begin{array}{l}\text { Number } \\
\text { of } \\
\text { enrollees } \\
\text { who } \\
\text { initiated } \\
\text { the } \\
\text { vaccine } \\
\text { series } \\
\text { and had } \\
\text { a well- } \\
\text { check } \\
\text { visit } \\
\text { during } \\
\text { the year }\end{array}$ & 103 & 584 & 534 & 537 & 23789 & 88985 & 192487 & 200976 & 197046 & 119667 & 144921 \\
\hline
\end{tabular}




\begin{tabular}{|c|c|c|c|c|c|c|c|c|c|c|c|}
\hline & \multicolumn{11}{|c|}{ Calendar Year } \\
\hline & 2006 & 2007 & 2008 & 2009 & 2010 & 2011 & 2012 & 2013 & 2014 & 2015 & 2016 \\
\hline $\begin{array}{l}\text { Percent } \\
\text { of those } \\
\text { who } \\
\text { initiated } \\
\text { the } \\
\text { vaccine } \\
\text { series } \\
\text { during } \\
\text { the year } \\
\text { who had } \\
\text { a well- } \\
\text { check } \\
\text { visit that } \\
\text { year }\end{array}$ & 83.1 & 78.5 & 76.9 & 82.6 & 88.8 & 89.0 & 90.8 & 90.6 & 90.2 & 91.3 & 91.1 \\
\hline
\end{tabular}

\subsection{Well-check Visit}

The proportion of subjects with a documented well-check visit by age and gender for 2016 is reported in Table 2. From year 2006 to 2016 , the annual proportion of those turning 9 to 18 years old who had a well-check visit increased from $29.7 \%$ (2006) to $49.0 \%$ (2016) among females, and from 28.5\% (2015) and 47.9\% (2016) among males (Table 1). Most of the children and adolescent who initiated HPV vaccine had at least one well-check visit the same year (year- and gender-specific proportions varied between $76.9 \%$ and $91.3 \%$, Table 1). The frequency of claims associated with either of the various ICD9/10 diagnosis codes or CPT procedure codes for well-check visits in year 2016 is reported as supplementary material (Table S2).

Table 2

Frequency of Well-Check Visits in 2016, by Age and Gender

\begin{tabular}{|lll|}
\hline Age (years) & \multicolumn{2}{l|}{ Proportion of Enrollees with a Well-Check Visit in $2016(\%)$} \\
\cline { 2 - 3 } & Males & Females \\
\hline 9 & 48.1 & 47.2 \\
\hline 10 & 46.9 & 46.1 \\
\hline 11 & 45.7 & 45.1 \\
\hline 12 & 53.3 & 53.8 \\
\hline 13 & 56.7 & 56.5 \\
\hline 14 & 51.8 & 50.0 \\
\hline 15 & 48.6 & 48.4 \\
\hline 16 & 45.8 & 47.1 \\
\hline 17 & 43.1 & 47.3 \\
\hline 18 & 40.2 & 48.3 \\
\hline 19 & 34.2 & 48.8 \\
\hline 20 & 21.8 & 43.5 \\
\hline 21 & 15.7 & 41.5 \\
\hline 22 & 13.8 & 43.3 \\
\hline 23 & 12.3 & 43.2 \\
\hline 26 & 11.7 & 42.7 \\
\hline
\end{tabular}

\subsection{Provider type}


Figure 2 shows the distribution of health care professionals who provided the initial HPV vaccine dose between 2006 and 2016 , according to age and gender of the vaccinated subjects. Pediatricians, family physicians, obstetricians/gynecologists and internists administered the first dose in $60.6 \%, 15.8 \%, 1.8 \%$ and $1.7 \%$ of girls turning 15 years old, respectively; among women 26 years old, the proportions were $0.6 \%$, $23.3 \%$, $44.2 \%$ and $7.9 \%$, respectively. Pediatrician, family physicians, and internists administered the first dose in $69.4 \%, 12.0 \%$ and $1.7 \%$ of boys turning 15 years old in comparison with $3.7 \%, 45.6 \%$ and $21.2 \%$ of men turning 26 years old, respectively (Fig. 2).

\section{Discussion}

We assessed HPV vaccine uptake in the US within a large claims database covering several million 9 to 26 years old children and young adults between 2006 and 2016. The study includes all the licensed HPV vaccines (20,21), and therefore provides a thorough analysis of vaccine uptake in the US and the extent of catch-up implementation during the 10-year period following HPV vaccine licensure (females in mid-2006 and males in late 2009) $(22,23)$.

Our results are consistent with another claims database-based study by the Blue Cross Blue Shield Association, (13) that reported a 32\% and $37 \%$ vaccine coverage for the 13 years old male and female adolescents in 2016 , compared with a cumulative uptake of $28.6 \%$ and $33.1 \%$ until age12-13 years old in this analysis, respectively. It is also consistent with the numbers from Gargano et al. (14) who used the same underlying MarketScan database but who applied a different methodology (in $2014,53.0 \%$ of females and $30.3 \%$ of males turning 17 or 18 years old had been vaccinated, versus about $51.7 \%$ of females and $30.9 \%$ of males using our uptake estimates) using restrictive inclusion criteria requiring more continuous follow-up. While claims based analysis of uptake from our study seem lower, they cannot be directly compared to National Health and Nutrition Examination Survey (NHANES) (15) or NIS-Teen (16), as they both are vaccination coverage studies that ask for vaccination during the lifetime.

The study provides insight into how a new ACIP recommendation for a vaccine is implemented in a real-world setting. When the HPV vaccine was approved for women in 2006, a broad slice of the population across different age groups got vaccinated. There was catchup vaccination uptake in older age group, with $10.6 \%$ of those turning 20 years old and $4.5 \%$ of those turning 26 years old receiving a dose of the vaccine. Over time, more and more teenagers were vaccinated at younger ages which means less were available for vaccination as older adolescents and young adults. This translated into higher uptake for young adolescents $(14.7 \%$ and $18.6 \%$ of those turning 12 and 13 years old, respectively) and lower uptake at older ages (1.1\% of those turning 26 years old) in 2016 . This pattern can be observed through the heat map. As vaccination is initiated, the hue is light green across a broader age range, including older adults. Moving to the right the cells start turning dark green for young adolescents indicating steadily increasing vaccination uptake for this group, whereas it gets lighter for older adolescent and young adults (Fig. 1). This shows that vaccination uptake is steadily increasing for adolescents. The uptakes remain red in those turning 9 or 10 years old, implying very few children receive a vaccine at that age. Our analysis shows that the vaccination completion target of $80 \%$ by 2026 among 13-years-olds is not likely to be achieved (12). The uptake rate was particularly low for young children with almost none of those turning 9 years old and less than $0.4 \%$ of those turning 10 initiating HPV vaccination in the US-this could be because ACIP does not specifically recommend to routinely vaccinate this age group. Thus, the ACIP recommendation appears more influential than the US FDA label for HPV vaccination. This is understandable as the ACIP recommendation drives coverage and reimbursement of the vaccine. Albeit the ACIP recommendation for HPV vaccine initiation at a targeted age of 11 or 12 years old (or before), of these turning 12 years of age in 2016 , only 1 in 6 girls and 1 in 7 boys received an HPV vaccination while half of them had a well-check visit.

The proportion of children and teenagers having a well-check visit increased gradually for both females and males. Our estimates are consistent with previously reported proportions of well-check visits in national surveys for these ages (24-26) and similar to estimates of adolescents and young adults aged 12 to 21 years old who had commercially insured well-care visits each year between 2006 and 2016 (27). Almost half of the young adolescent population had a well-check visit. Visits tapered for both men and women, and more drastically for men. This is consistent with the literature that shows that women have better health-seeking behaviors(28). Low well-check rates is a lost opportunity for vaccination as these visits constitute one of the best routes for initiating or completing vaccination series-more than $90 \%$ of those who initiated a vaccination series in 2016 also had a well-check visit that year.

Our study also shows that the type of provider for HPV vaccine changes as children age. Pediatricians administer most of the HPV vaccination for children, followed by family physicians. As children grow, their visits to pediatricians decline. In young adulthood, HPV vaccination is mostly picked up by obstetrician/gynecologists for women, and by family physicians and other primary care physicians for men. Among both females and males, a very small proportion had their initial HPV vaccine administered by a nurse practitioner or a physician assistant. These data are important as healthcare providers who administer the vaccine are known to address parental safety concerns, and help promote positive beliefs about vaccination; physician recommendation often is identified as among the most important determinants of HPV vaccination coverage $(29,30)$. Our description of who initiates the HPV vaccine series, and in what setting can also be very helpful for implementing interventions aimed at maintaining and improving overall vaccination coverage in specific target populations. For example, wellcheck visits are recommended once a year in adolescents children and interventions targeted to improve the rate of well-check visits in

Page 8/13 
pediatricians' office may help increase HPV vaccination uptake in this age group $(29,31)$. Interventions that improve well-check visits in older adults can help improve vaccination uptakes in those populations.

Several limitations apply to this study including those inherent to administrative claims database analyses such as misclassification, upcoding and under coding. The study population is also limited to a commercially insured population which may not allow for generalizing the results to the entire US, for example, access to care may differ in the overall population, especially those getting vaccinated under the Vaccines for Children (VFC) program. We also could not identify vaccines not submitted for insurance reimbursement nor those that were received out-of- network as for example, enrollees were not all continuously in the database since 2006. Only non-missing values were considered, and no imputation of missing information was carried out. Lastly only birth year, was available so vaccine coverage by exact year age could not be determined.

\section{Conclusions}

We found that the ACIP vaccine recommendations directly impact HPV vaccination uptake in the population. When the HPV vaccination program started in 2006 for females and 2009 for males, there was catch-up in a broader age-group, followed by increase in vaccine uptake among targeted young cohorts. While females had a head start (with early inclusion in the label for HPV vaccination) vaccination uptake in males is fast catching up. While uptake in young adolescents has been increasing, it remains far below the $80 \%$ goal, and catch-up vaccination in older cohorts is likely to continue into the near future as many children remain unvaccinated as they get older. Pediatricians, followed by family physicians remain the primary vaccine administrators for adolescents. Obstetrician/gynecologists and family physicians commonly vaccinate young adult women and young adult men, respectively. Thus, interventions to improve uptake should consider focusing on pediatricians and family physicians for children, and obstetrician/gynecologists and family physicians for young adults. Interventions to improve access to well-check visits and HPV vaccination within well-check visits should also be considered to improve HPV uptake. Our study provides an analysis of how many children and young adults get vaccinated, when, by whom, and in what context. Understanding this can guide the development of appropriate interventions and policies to help improve vaccination uptake and public health.

\section{Abbreviations}

HPV, Human papillomavirus; US, United States; ACIP, Advisory Committee for Immunization Practices; HIV, after Human Immunodeficiency Virus; 4vHPV, quadrivalent HPV vaccine; 2vHPV, bivalent HPV vaccine; 9vHPV, nonavalent HPV vaccine; ACS, American Cancer Society; NHANES, National Health and Nutrition Examination Survey; NIS-Teen, National Immunization Survey-Teen; NHIS, National Health Interview Survey; CPT, Current Procedure Terminology; ICD, an International Classification of Disease; VFC, Vaccines for Children;

\section{Declarations}

\section{Ethics approval and consent to participate}

IBM provided de-identified individual-level data from the IBM MarketScan Research Database which are fully compliant with U.S. privacy laws and regulations, i.e. the Health Insurance Portability and Accountability Act (HIPAA), and no IRB clearance was necessary.

\section{Consent for publication}

Not Applicable

\section{Availability of data and materials}

The study is based on de-identified individual-level data from a secondary administrative healthcare claims database (IBM ${ }^{\circledR}$ MarketScan ${ }^{\circledR}$ Research Database) which are fully compliant with U.S. privacy laws and regulations, i.e. the Health Insurance Portability and Accountability Act (HIPAA). The data that support the findings of this study are available from IBM ${ }^{\circledR}$ MarketScan ${ }^{\circledR}$ Research Databases, but restrictions apply to the availability of these data, which were used under license for the current study, and so are not publicly available. Data are however available from the authors upon reasonable request and with permission of IBM® Watson Health ${ }^{\mathrm{TM}}$.

\section{Competing interests}

VSP, ZL, RF, SK and KT are employees of Merck Sharp \& Dohme Corp., a subsidiary of Merck \& Co., Inc., Kenilworth, NJ, USA and potentially own stock and/or hold stock options in Merck \& Co., Inc., Kenilworth, NJ, USA. NB and MS are employees of CHEORS, which has done contract work from Merck \& Co., Inc. EM reports personal fees from Merck \& Co., Inc. during the conduct of the study and outside the submitted work, personal fees from Hologic, Inc., AbbVie, Inc., and Bayer, Inc. 


\section{Funding}

Funding for this research was provided by Merck Sharp \& Dohme Corp., a subsidiary of Merck \& Co., Inc., Kenilworth, NJ, USA.

\section{Authors' contributions}

VSP, ZL, EM, and SK participated in the study design, the analysis of the data, the interpretation of findings and the development of the manuscript. NB participated in the acquisition of the data, analysis of the data and interpretation of findings. MS participated in the interpretation of the findings and the development of the manuscript. RF and KT participated in the analysis of the data and the interpretation of the findings. All authors critically reviewed the manuscript and approved the final version for journal submission.

\section{Acknowledgements:}

None.

\section{References}

1. Dunne EF, Markowitz LE, Saraiya M, Stokley S, Middleman A, Unger ER, et al. CDC grand rounds: Reducing the burden of HPV-associated cancer and disease. Morbidity and Mortality Weekly Report. 2014.

2. Gillison ML, Chaturvedi AK, Lowy DR. HPV prophylactic vaccines and the potential prevention of noncervical cancers in both men and women. Cancer. 2008.

3. Van Dyne EA, Henley SJ, Saraiya M, Thomas CC, Markowitz LE, Benard VB. Trends in human papillomavirus-associated cancers United States, 1999-2015. Morbidity and Mortality Weekly Report. 2018.

4. Owusu-Edusei K, Chesson HW, Gift TL, Tao G, Mahajan R, Ocfemia MCB, et al. The estimated direct medical cost of selected sexually transmitted infections in the United States, 2008. Sex Transm Dis. 2013.

5. Petrosky E, Bocchini JA, Hariri S, Chesson H, Curtis RC, Saraiya M, et al. Use of 9-valent human papillomavirus (HPV) vaccine: Updated hpv vaccination recommendations of the advisory committee on immunization practices. Morb Mortal Wkly Rep. 2015.

6. Gee J, Weinbaum C, Sukumaran L, Markowitz LE. Quadrivalent HPV vaccine safety review and safety monitoring plans for nine-valent HPV vaccine in the United States. Human Vaccines and Immunotherapeutics. 2016.

7. Cervarix[Human Papillomavirus Bivalent. (Types 16 and 18) Vaccine, Recombinant] [Internet]. [cited 2020 Apr 30]. Available from: https://www.fda.gov/media/78013/download.

8. HPV Vaccine Implementation Guidance [Internet]. 2017 [cited 2020 Apr 30]. Available from: https://www.aap.org/enus/Documents/immunization_hpvimplementationguidance.pdf.

9. Markowitz LE, Dunne EF, Saraiya M, Chesson HW, Curtis CR, Gee J, et al. Human Papillomavirus Vaccination Recommendations of the Advisory Committee on Immunization Practices (ACIP). MMWR Recomm Reports. 2014.

10. Meites E, Szilagyi PG, Chesson HW, Unger ER, Romero JR, Markowitz LE. Human papillomavirus vaccination for adults: Updated recommendations of the advisory committee on immunization practices. Morb Mortal Wkly Rep. 2019.

11. Chesson H. Overview of Health Economic Models for HPV Vaccination of Mid-Adults [Internet]. 2019 [cited 2020 Apr 30]. Available from: https://www.cdc.gov/vaccines/acip/meetings/downloads/slides-2019-06/HPV-4-Chesson-508.pdf.

12. American Cancer Society Launches Campaign to Eliminate Cervical Cancer [Internet]. 2018 [cited 2020 Apr 27]. Available from: http://pressroom.cancer.org/HPVcancerfreelaunch.

13. Adolescent vaccination rates in America. | Blue Cross Blue Shield [Internet]. [cited 2020 Apr 27]. Available from: https://www.bcbs.com/the-health-of-america/reports/adolescent-vaccination-rates-in-america.

14. Gargano JW, Zhou F, Stokley S, Markowitz LE. Human papillomavirus vaccination in commercially-insured vaccine-eligible males and females, United States, 2007-2014. Vaccine. 2018.

15. Lewis RM, Markowitz LE. Human papillomavirus vaccination coverage among females and males, National Health and Nutrition Examination Survey, United States, 2007-2016. Vaccine. 2018.

16. Walker TY, Elam-Evans LD, Singleton JA, Yankey D, Markowitz LE, Fredua B, et al. National, regional, state, and selected local area vaccination coverage among adolescents aged 13-17 years - United States, 2016. Morb Mortal Wkly Rep. 2017.

17. Williams WW, Lu PJ, O'Halloran A, Kim DK, Grohskopf LA, Pilishvili T, et al. Surveillance of vaccination coverage among adult populationsUnited States, 2015. MMWR Surveill Summ. 2017.

18. Recommendations for Preventive Pediatric Health Care. 2015 [cited 2020 Apr 27]; Available from: http://pediatrics.aappublications.org/cgi/doi/10.1542/peds.2014-1699.

Page $10 / 13$ 
19. AAP Schedule of Well-Child Care Visits. - HealthyChildren.org [Internet]. [cited 2020 Apr 27]. Available from: https://www.healthychildren.org/English/family-life/health-management/Pages/Well-Child-Care-A-Check-Up-for-Success.aspx.

20. FDA approves expanded use of Gardasil. 9 to include individuals 27 through 45 years old | FDA [Internet]. [cited 2020 Apr 27]. Available from: https://www.fda.gov/news-events/press-announcements/fda-approves-expanded-use-gardasil-9-include-individuals-27-through-45years-old.

21. Human Papillomavirus (HPV) Vaccines. - National Cancer Institute [Internet]. [cited 2020 Apr 27]. Available from: https://www.cancer.gov/about-cancer/causes-prevention/risk/infectious-agents/hpv-vaccine-fact-sheet.

22. Gardasil Vaccine Safety | FDA [Internet]. 2009 [cited 2020 Apr 27]. Available from: https://www.fda.gov/vaccines-blood-biologics/safetyavailability-biologics/gardasil-vaccine-safety.

23. Schwartz JL. HPV vaccination's second act: Promotion, competition, and compulsion. American Journal of Public Health. 2010.

24. Caldwell J, Berdahl T. Trends in Well-Child Visits: United States, 2002-2009. In 2001.

25. Black LI, Nugent CN, Vahratian A. Access and Utilization of Selected Preventive Health Services Among Adolescents Aged 10-17. NCHS Data Brief. 2016.

26. Uddin SG, O'Connor KS, Ashman JJ. Physician Office Visits by Children for Well and Problem-focused Care: United States, 2012. NCHS Data Brief. 2016.

27. Child and Adolescent Well-Care Visits. - NCQA [Internet]. [cited 2020 Apr 30]. Available from: https://www.ncqa.org/hedis/measures/childand-adolescent-well-care-visits/.

28. Pinkhasov RM, Wong J, Kashanian J, Lee M, Samadi DB, Pinkhasov MM, et al. Are men shortchanged on health? Perspective on health care utilization and health risk behavior in men and women in the United States. International Journal of Clinical Practice. 2010.

29. Holman DM, Benard V, Roland KB, Watson M, Liddon N, Stokley S. Barriers to human papillomavirus vaccination among us adolescents a systematic review of the literature. JAMA Pediatrics. 2014.

30. Newman PA, Logie CH, Lacombe-Duncan A, Baiden P, Tepjan S, Rubincam C, et al. Parents' uptake of human papillomavirus vaccines for their children: A systematic review and meta-analysis of observational studies. BMJ Open. 2018.

31. Shah PD, Gilkey MB, Pepper JK, Gottlieb SL, Brewer NT. Promising alternative settings for HPV vaccination of US adolescents. Expert Review of Vaccines. 2014.

\section{Figures}


a. Females

\begin{tabular}{|c|c|c|c|c|c|c|c|c|c|c|c|c|c|}
\hline \multirow{2}{*}{$\begin{array}{c}\text { Year of } \\
\text { birth in } \\
\text { column } \\
2006\end{array}$} & \multirow{2}{*}{$\begin{array}{c}\text { Age } \\
\text { (years) }\end{array}$} & \multicolumn{11}{|c|}{ Percent of Female Who Received a First Dose of HPV Vaccine, by Calendar Year (number of enrollees) } & \multirow{2}{*}{$\begin{array}{c}\text { Year of } \\
\text { birth in } \\
\text { column } \\
2016\end{array}$} \\
\hline & & $\begin{array}{c}2006 \\
(4,281,371) \\
\end{array}$ & $\begin{array}{c}2007 \\
(4,425,651)\end{array}$ & $\begin{array}{c}2008 \\
(4,617,104)\end{array}$ & $\begin{array}{c}2009 \\
(5,268,901) \\
\end{array}$ & $\begin{array}{c}2010 \\
(5,919,457)\end{array}$ & $\begin{array}{c}2011 \\
(6,973,660)\end{array}$ & $\begin{array}{c}2012 \\
(7,158,058)\end{array}$ & $\begin{array}{c}2013 \\
(5,925,013) \\
\end{array}$ & $\begin{array}{c}2014 \\
(6,347,083)\end{array}$ & $\begin{array}{c}2015 \\
(3,833,453) \\
\end{array}$ & $\begin{array}{c}2016 \\
(3,758,091)\end{array}$ & \\
\hline 1997 & $8-9$ & 0.00 & 0.00 & 0.00 & 0.00 & 0.00 & 0.00 & 0.00 & 0.00 & 0.00 & 0.00 & 0.00 & 2007 \\
\hline 1996 & $9-10$ & 0.10 & 0.50 & 0.40 & 0.30 & 0.30 & 0.30 & 0.30 & 0.30 & 0.30 & 0.30 & 0.40 & 2006 \\
\hline 1995 & $10-11$ & 0.20 & 1.40 & 1.00 & 0.80 & 0.70 & 0.80 & 0.80 & 0.80 & 0.70 & 0.70 & 0.90 & 2005 \\
\hline 1994 & $11-12$ & 0.80 & 5.80 & 5.40 & 5.50 & 6.00 & 7.50 & 8.50 & 10.40 & 10.90 & 12.40 & 15.60 & 2004 \\
\hline 1993 & $12-13$ & 1.10 & 9.90 & 9.00 & 9.10 & 9.00 & 10.80 & 12.10 & 14.70 & 14.80 & 15.90 & 19.70 & 2003 \\
\hline 1992 & $13-14$ & 1.30 & 11.10 & 9.40 & 8.20 & 8.00 & 9.30 & 9.80 & 11.80 & 11.30 & 11.40 & 13.90 & 2002 \\
\hline 1991 & $14-15$ & 1.50 & 13.50 & 11.30 & 8.80 & 7.70 & 8.70 & 9.20 & 10.70 & 9.50 & 9.00 & 10.70 & 2001 \\
\hline 1990 & $15-16$ & 1.70 & 14.20 & 11.40 & 8.50 & 6.90 & 7.50 & 7.70 & 9.10 & 7.90 & 7.40 & 8.30 & 2000 \\
\hline 1989 & 16-17 & 1.80 & 14.30 & 11.00 & 7.80 & 6.10 & 6.20 & 6.10 & 7.40 & 6.50 & 6.20 & 7.00 & 1999 \\
\hline 1988 & $17-18$ & 1.90 & 14.20 & 10.60 & 7.20 & 5.30 & 5.40 & 5.00 & 5.90 & 5.50 & 5.30 & 6.20 & 1998 \\
\hline 1987 & 18-19 & 1.80 & 15.00 & 11.30 & 7.70 & 5.40 & 5.00 & 5.00 & 5.50 & 4.90 & 4.80 & 5.60 & 1997 \\
\hline 1986 & $19-20$ & 1.30 & 10.60 & 7.40 & 5.10 & 3.50 & 3.00 & 2.80 & 2.90 & 2.50 & 2.40 & 2.90 & 1996 \\
\hline 1985 & $20-21$ & 1.20 & 8.50 & 6.40 & 3.90 & 2.50 & 2.10 & 1.80 & 1.80 & 1.50 & 1.40 & 1.70 & 1995 \\
\hline 1984 & $21-22$ & 1.00 & 7.20 & 5.90 & 4.00 & 2.30 & 1.90 & 1.70 & 1.70 & 1.30 & 1.30 & 1.50 & 1994 \\
\hline 1983 & $22-23$ & 0.80 & 5.90 & 5.20 & 3.70 & 2.50 & 2.00 & 1.70 & 1.70 & 1.30 & 1.30 & 1.50 & 1993 \\
\hline 1982 & $23-24$ & 0.70 & 5.10 & 4.70 & 3.60 & 2.50 & 2.20 & 1.80 & 1.70 & 1.30 & 1.30 & 1.50 & 1992 \\
\hline 1981 & $24-25$ & 0.60 & 4.80 & 4.60 & 3.70 & 2.50 & 2.30 & 2.10 & 1.70 & 1.40 & 1.30 & 1.50 & 1991 \\
\hline 1980 & $25-26$ & 0.60 & 4.50 & 4.30 & 3.60 & 2.50 & 2.30 & 2.10 & 1.90 & 1.40 & 1.40 & 1.50 & 1990 \\
\hline $1980-97$ & Total & 1.08 & 8.14 & 6.63 & 5.08 & 4.09 & 4.29 & 4.36 & 5.00 & 4.61 & 4.66 & 5.58 & $1990-06$ \\
\hline
\end{tabular}

\section{b. Males}

\begin{tabular}{|c|c|c|c|c|c|c|c|c|c|c|c|c|c|}
\hline \multirow{2}{*}{$\begin{array}{c}\text { Year of } \\
\text { birth in } \\
\text { column } \\
2006\end{array}$} & \multirow{2}{*}{$\begin{array}{c}\text { Age } \\
\text { (years) }\end{array}$} & \multicolumn{11}{|c|}{ Percent of Male Who Received a First Dose of HPV Vaccine, by Calendar Year (number of enrollees) } & \multirow{2}{*}{$\begin{array}{c}\text { Year of } \\
\text { birth in } \\
\text { column } \\
2016\end{array}$} \\
\hline & & \begin{tabular}{c|c|}
2006 \\
$(4,334,261)$ \\
\end{tabular} & $\begin{array}{c}2007 \\
(4,481,856) \\
\end{array}$ & $\begin{array}{c}2008 \\
(4,657,911) \\
\end{array}$ & $\begin{array}{c}2009 \\
(5,304,668)\end{array}$ & $\begin{array}{c}2010 \\
(6,034,528) \\
\end{array}$ & \begin{tabular}{|c|}
2011 \\
$(7,185,946)$ \\
\end{tabular} & $\begin{array}{c}2012 \\
(7,396,051) \\
\end{array}$ & \begin{tabular}{c|c|}
2013 \\
$(6,107,104)$ \\
\end{tabular} & \begin{tabular}{|c|}
2014 \\
$(6,567,907)$ \\
\end{tabular} & \begin{tabular}{|c|}
2015 \\
$(3,926,599)$ \\
\end{tabular} & $\begin{array}{c}2016 \\
(3,846,246)\end{array}$ & \\
\hline 1997 & 8-9 & 0.00 & 0.00 & 0.00 & 0.00 & 0.00 & 0.00 & 0.00 & 0.00 & 0.00 & 0.00 & 0.00 & 2007 \\
\hline 1996 & $9-10$ & 0.00 & 0.00 & 0.00 & 0.00 & 0.10 & 0.10 & 0.20 & 0.20 & 0.20 & 0.20 & 0.30 & 2006 \\
\hline 1995 & $10-11$ & 0.00 & 0.00 & 0.00 & 0.00 & 0.10 & 0.30 & 0.40 & 0.50 & 0.50 & 0.50 & 0.70 & 2005 \\
\hline 1994 & $11-12$ & 0.00 & 0.00 & 0.00 & 0.00 & 0.80 & 2.30 & 5.10 & 7.50 & 8.70 & 10.30 & 13.80 & 2004 \\
\hline 1993 & $12-13$ & 0.00 & 0.00 & 0.00 & 0.00 & 1.10 & 3.40 & 7.60 & 10.70 & 12.00 & 13.40 & 17.60 & 2003 \\
\hline 1992 & $13-14$ & 0.00 & 0.00 & 0.00 & 0.00 & 1.10 & 3.50 & 7.60 & 10.20 & 9.80 & 10.30 & 13.50 & 2002 \\
\hline 1991 & $14-15$ & 0.00 & 0.00 & 0.00 & 0.00 & 1.20 & 3.90 & 8.40 & 10.60 & 9.40 & 9.20 & 10.90 & 2001 \\
\hline 1990 & $15-16$ & 0.00 & 0.00 & 0.00 & 0.00 & 1.20 & 4.00 & 8.50 & 10.50 & 8.80 & 7.90 & 8.90 & 2000 \\
\hline 1989 & $16-17$ & 0.00 & 0.00 & 0.00 & 0.00 & 1.20 & 3.90 & 8.10 & 9.80 & 7.90 & 6.90 & 7.60 & 1999 \\
\hline 1988 & $17-18$ & 0.00 & 0.00 & 0.00 & 0.00 & 1.00 & 3.60 & 7.40 & 8.80 & 7.10 & 6.10 & 6.80 & 1998 \\
\hline 1987 & $18-19$ & 0.00 & 0.00 & 0.00 & 0.00 & 0.80 & 3.00 & 6.40 & 7.80 & 6.30 & 5.40 & 5.80 & 1997 \\
\hline 1986 & $19-20$ & 0.00 & 0.00 & 0.00 & 0.00 & 0.40 & 1.50 & 3.20 & 4.00 & 3.10 & 2.60 & 2.70 & 1996 \\
\hline 1985 & $20-21$ & 0.00 & 0.00 & 0.00 & 0.00 & 0.20 & 0.70 & 1.60 & 2.00 & 1.40 & 1.20 & 1.40 & 1995 \\
\hline 1984 & $21-22$ & 0.00 & 0.00 & 0.00 & 0.00 & 0.10 & 0.40 & 1.00 & 1.30 & 1.10 & 0.90 & 1.00 & 1994 \\
\hline 1983 & $22-23$ & 0.00 & 0.00 & 0.00 & 0.00 & 0.10 & 0.30 & 0.60 & 0.80 & 0.70 & 0.70 & 0.80 & 1993 \\
\hline 1982 & 23-24 & 0.00 & 0.00 & 0.00 & 0.00 & 0.10 & 0.20 & 0.40 & 0.50 & 0.50 & 0.50 & 0.70 & 1992 \\
\hline 1981 & $24-25$ & 0.00 & 0.00 & 0.00 & 0.00 & 0.10 & 0.10 & 0.30 & 0.40 & 0.50 & 0.50 & 0.60 & 1991 \\
\hline 1980 & $25-26$ & 0.00 & 0.00 & 0.00 & 0.00 & 0.10 & 0.20 & 0.30 & 0.40 & 0.40 & 0.50 & 0.70 & 1990 \\
\hline $1980-97$ & Total & 0.00 & 0.00 & 0.00 & 0.00 & 0.54 & 1.74 & 3.73 & 4.78 & 4.36 & 4.28 & 5.21 & $1990-06$ \\
\hline
\end{tabular}

\section{Figure 1}

Annual HPV Vaccination Uptake From 2006 to 2016 Among 9- to 26-Years-Olds of the United States: (a) Females and (b) Males. The annual uptakes are calculated as the proportion of unique enrollees of same age and gender who had a first claim for an HPV vaccine during the year. The colors in the graph depict the uptake pattern observed over time with colors transitioning from red to green as uptake values get higher. Each year, subjects turning between 9 and 26 years old are included (in 2006, enrollees born between 1980 and 1997, and in 2016, subjects are born between 1990 and 2007). Each column provides the annual uptakes by subjects' year of age as determined by year of birth (in 2006, the 9-10 years-old subjects are those turning 10 during the year, i.e. the 1996 newborns). Birth cohort annual uptake estimates are found on decreasing diagonals. For example, $0.5 \%$ and $5.6 \%$ of enrollees born in 1997 initiated HPV vaccination in 2007 and 2016 , respectively. 


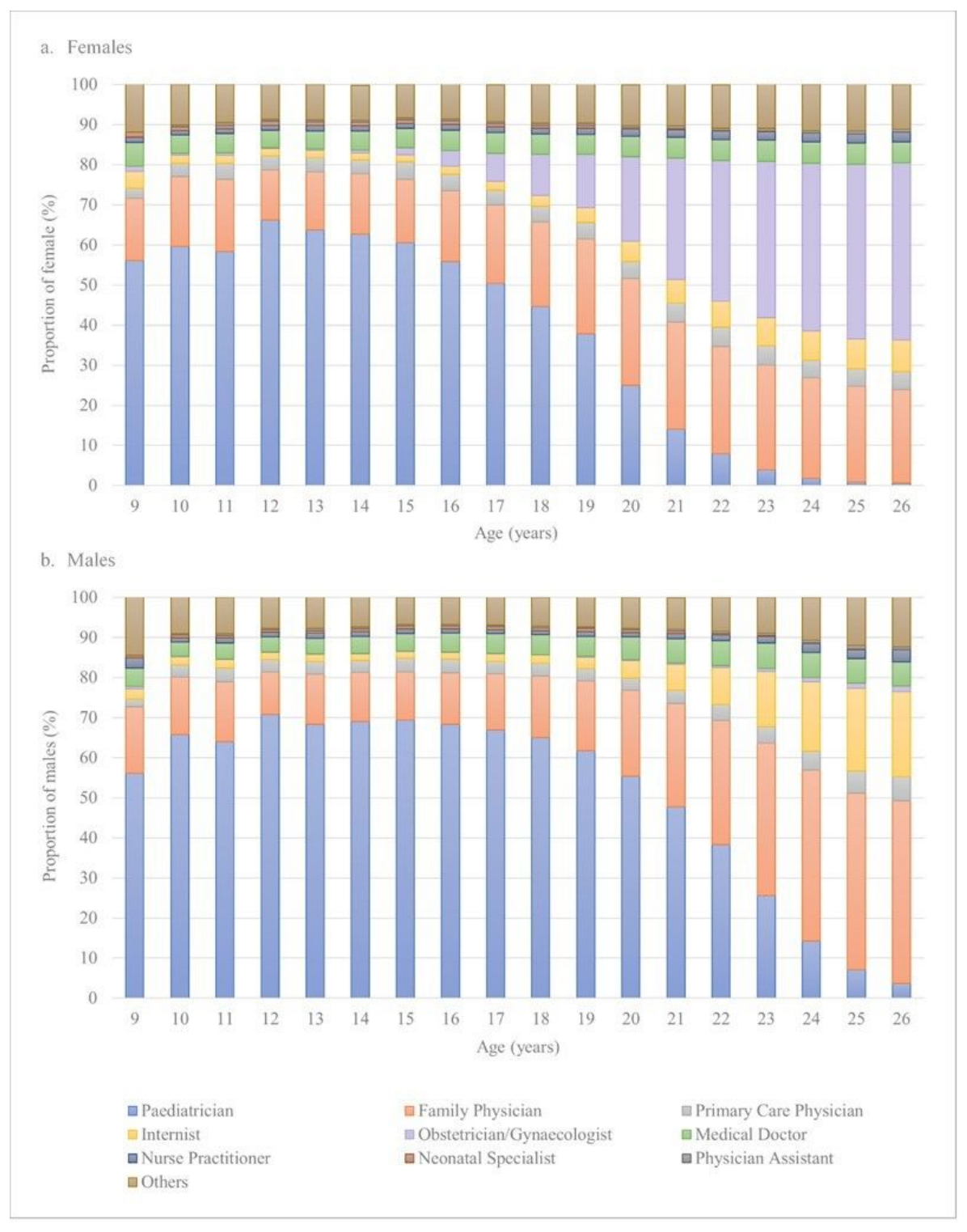

\section{Figure 2}

Distribution of Initial HPV Vaccine Dose Providers According to Patient Age and Gender Between 2006 and 2016 Among 9- to $26-Y e a r s-O l d s ~ o f$ the United States: (a) Females and (b) Males. Subjects' year of age was determined by year of birth (e.g. the 9-years-olds are those who turned 9 the year they received their first HPV vaccine).

\section{Supplementary Files}

This is a list of supplementary files associated with this preprint. Click to download.

- Supplementary.docx 